\title{
O grupo Vriesea platynema Gaudich. (Bromeliaceae: Tillandsioideae) no estado do Paraná, Brasil
}

The group Vriesea platynema Gaudich. (Bromeliaceae: Tillandsioideae) in Paraná State, Brazil

\author{
Vanessa Koza Kowalski ${ }^{1,2}$ \& Rosângela Capuano Tardivo ${ }^{1}$
}

\begin{abstract}
Resumo
Vriesea é o segundo maior gênero de Tillandsioideae com 281 espécies, distribuído predominantemente na América do Sul. No Brasil, as espécies ocorrem no Cerrado, na Amazônia, na Caatinga, Pampa e principalmente na Mata Atlântica, bioma com a maior riqueza específica do gênero. Na sistemática atual, Vriesea está dividido em duas secções, Vriesea e Xiphion. Na secção Xiphion enquadra-se grande parte do grupo V. platynema com 41 espécies, ocorrendo desde a América Central até a Argentina. O grupo apresenta acentuado polimorfismo, proporcionando a identificação errônea dos táxons. Neste estudo, são reconhecidos três táxons para o Paraná, V. platynema var. platynema, V. platynema var. variegata e $V$. tijucana. Para cada táxon, são apresentadas descrições morfológicas, comentários, chave de identificação, distribuição geográfica, ilustrações e o status de conservação.

Palavras-chave: Flora do Paraná, Taxonomia, Xiphion.
\end{abstract}

\begin{abstract}
Vriesea is the second largest genus in Tillandsioideae with 281 species, distributed mainly in South America. In Brazil, occur at Cerrado, Amazon, Caatinga, Pampa and mainly in the Atlantic Rain Forest biome with the highest species richness of the genus. In the current systematic, Vriesea is divided into two sections, Vriesea and Xiphion. The section Xiphion is the largest of the group V. platynema with 41 species, occurring from Central America to Argentina. It has a high polymorphism, leading to misidentification of taxa. In this study, three taxa are recognized to Paraná State: $V$. platynema var. platynema, $V$. platynema var. variegata and $V$. tijucana. Descriptions, comments, key identification, geographical distribution, conservation status and illustrations are presented.
\end{abstract}

Key words: Flora of Paraná, Taxonomic study, Xiphion.

\section{Introdução}

Bromeliaceae compreende 58 gêneros e aproximadamente 3.352 espécies (Luther 2012) que estão distribuídas em três centros de diversidade: 0 leste do Brasil, o Planalto das Guianas entre o Norte dos Andes até o México e Antilhas (Benzing 2000). Caracteriza-se pela captação e armazenamento de água e detritos em tanques formados pela sobreposição das bases foliares, pela absorção de água e nutrientes através dos tricomas foliares, utilização do ciclo fotossíntético CAM e pelo epifitismo. Estas características possibilitam a vida em ambientes diversos e extremos, e contribuindo para a sua ampla distribuição (Benzing 2000; Martinelli et al. 2008; Givnish et al. 2014).

Recentemente, análises filogenéticas reconhecem oito subfamílias monofiléticas:
Brocchinioideae, Lindmanioideae, Tillandsioideae, Hechtioideae, Navioideae, Pitcairnioideae, Puyoideae e Bromelioideae (Givinish et al. 2007; Givinish et al. 2011).

Vriesea Lindl. (Tillandsioideae) ocorre predominantemente na América do Sul com a maior riqueza especifica na Mata Atlântica Brasileira, ocorrendo também no Cerrado, Amazônia, Caatinga e Pampa (Forzza et al. 2014; Wanderley \& Martins 2007). Está dividido em duas secções parafiléticas Vriesea com flores de antese diurna, brácteas florais coloridas, do vermelho ao amarelo, pétalas liguladas e estames exsertos; e Xiphion E. Morren ex Mez com flores de antese noturna, brácteas florais verdes a castanhas, pétalas obovais e estames inclusos (Smith \& Downs 1977; Wanderley \& Martins 2007; Gomesda-Silva et al. 2012).

\footnotetext{
${ }^{1}$ Universidade Estadual de Ponta Grossa, Campus Uvaranas, Av. General Carlos Cavalcanti 4748, 84030-900, Ponta Grossa, PR, Brasil.

${ }^{2}$ Autor para correspondência: vanessakkowalski@gmail.com
} 
O grupo Vriesea platynema (Sec. Xiphion) emergiu de um clado identificável pela inflorescência simples, de uma análise filogenética do gênero realizado por Costa (2002). Recentemente, revisadado por Moura (2011), o grupo é formado por 41 espécies com inflorescência simples ou composta e filetes alargados em direção ao ápice ou filiformes, achatados dorso-ventralmente.

Este estudo descreve as variações morfológicas em populações naturais de espécies de Vriesea sec. Xiphion com inflorescência simples, visando à identificação, o conhecimento da distribuição geográfica e o status de conservação dos táxons encontrados no estado do Paraná.

\section{Material e Métodos}

Expedições botânicas foram realizadas no Domínio Mata Atlântica, em todas as unidades fitogeográficas: Floresta Ombrófila Densa, Floresta Ombrófila Mista, Floresta Estacional Semidecidual, Formações Campestres e Cerrado (Roderjan et al. 2002), no estado do Paraná, no período de março de 2011 a outubro de 2012.

O material coletado florido e/ou frutificado foi herborizado utilizando as técnicas usuais em taxonomia vegetal descritos por Fidalgo \& Bononi (1989), sendo posteriormente depositado no HUPG.

Foram examinadas as coleções dos Herbários com uma coleção relevante da família Bromeliaceae: RB, EFC, FUEL, HBR, HUEM, HUPG, MBM, SP e UPCB e herbário virtual INCT. Foram analisados os exemplares em cultivo da coleção do Instituto de Botânica de São Paulo. Para a terminologia morfológica foram utilizadas literaturas especificas como Radford et al. (1974), Scharf \& Gouda (2008) e Gonçalves \& Lorenzi (2011). A terminologia do estigma foi baseada em Brown \& Gilmartin (1989).

O material coletado foi identificado com base em Smith (1955), Smith \& Downs (1977), Reitz (1983) e Moura (2011) e análise das descrições originais e imagens dos typus.

Para a avaliação do status de conservação dos táxons, utilizou-se os critérios estabelecidos pela IUCN (2001, 2012). Para a elaboração do mapa de distribuição, extensão de ocorrência e ocupação, foram utilizados os programas Quantum Gis 1.8 e Corel Draw, a partir das cordenadas do material coletado e examinado.

\section{Resultados e Discussão}

No estado do Paraná, o grupo é representado por Vriesea platynema Gaudich. var. platynema,
V. platynema var. variegata (Guillon) Reitz e $V$. tijucana E. Pereira. São encontradas principalmente na costa Atlântica, em Floresta Ombrofila Densa, e se interiorizam até o terceiro planalto Paranaense, em Floresta Ombrofila Mista e Formações Campestres (Fig.1).

Vriesea sec. Xiphion no Paraná são ervas epífitas, humícolas ou rupícolas, xerofíticas ou mesofíticas, $80-160 \mathrm{~cm}$ alt. Roseta

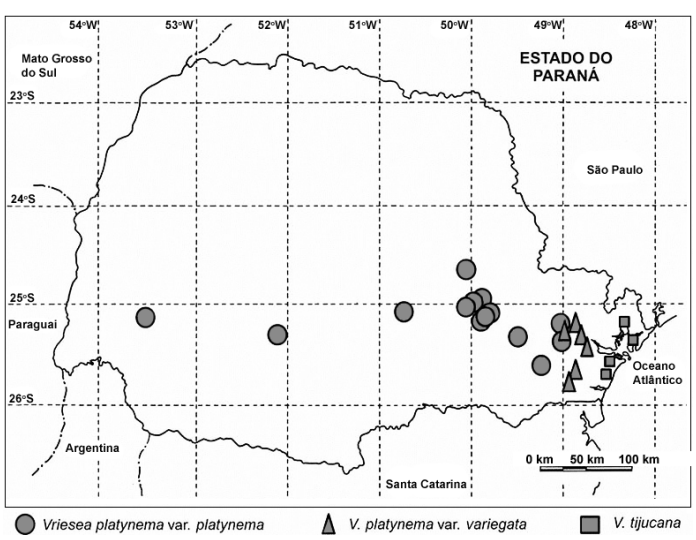

Figura 1 - Mapa de distribuição geográfica do Grupo Vriesea platynema no estado do Paraná. (mapa modificado de IPARDES 2011).

Figure 1 - Geographic distribution map of Vriesea platynema Group in Parana state (map modifield of IPARDES 2011).

infundibuliforme formando tanque. Folhas com distinção entre bainha e lâmina; bainha oval ou elíptica, densamente lepidota; lâmina linear ou lanceolada, com ápice obtuso-acuminado, levemente lepidota, inteiramente verde ou com estrias irregularmente dispostas em toda sua extensão ou com máculas vináceaes ou avermelhadas no ápice. Escapo bem desenvolvido, emergindo do centro da roseta, ereto ou subereto, superando as folhas; brácteas do escapo oval a largo-oval, amplexicaules, maiores que os entrenós. Inflorescência racemo. Brácteas florais oval, largo-oval ou largo-elípticas, mais curtas ou igualando-se às sépalas, amplexifloros, coriáceas, mucilaginosas. Flores dísticas, curto pediceladas, de antese noturna ou diurna; sépalas oblongas ou elípticas, livres, imbricadas; pétalas oblongas, oboval ou elípticas, curto-conatas, membranáceas, formando uma corola urceolada ou campanulada, com dois apêndices petalíneos adnatos a base, oval ou elípticos; estames inclusos, livres, sigmoides, 
achatados dorso-ventralmente, alargados em direção ao ápice; anteras introrsas, dorsifixas, rimosas, não versáteis; estigma laminar-convoluto. Fruto cápsula septícida; sementes fusiformes, plumosas.
Neste grupo, entre as características que mais se destacam estão os estames sigmoides, achatados dorso-ventralmente e alargados em direção ao ápice, além do odor exalado pelas flores e a presença de mucilagem nas mesmas.

\section{Chave de identificação das espécies do grupo Vriesea platynema Gaudich. para o estado do Paraná.}

1. Folhas $>60 \mathrm{~cm}$ compr.; inflorescência $40-70$ flores. Vriesea tijucana

1'. Folhas com até $60 \mathrm{~cm}$ compr., inflorescência com até 36 flores.

2. Lâmina foliar com estrias verde-escuras, sinuosas, irregularmente dispostas; corola urceolada ... Vriesea platynema var. platynema

2'. Lâmina foliar com estrias alvas, longitudinais em folhas jovens, mácula arroxeada ou avermelhada no ápice da face adaxial e vinácea na face abaxial; corola campanulada Vriesea platynema var. variegata

Vriesea platynema Gaudich. var. platynema Voy. Bonite, Bot.: 66. 1843. Typus: Brasil, Rio de Janeiro: Rio de Janeiro, s.d., fl., Gaudichaud-Beaupré s.n. (holotypus P 90.143 [imagem!]). Sinônimos: Vriesea corallina Regel., Gartenflora 19: 353. 1870. Encholirium corallinum (Regel) Linden ex André. III. Hort. 18: 136. 1871. Tillandsia corallina (Regel) K. Koch., App. Ind. Sem. Hort. Berol.: 5. 1874.

Figs: 2a-d, 3a-p

Planta florida, $80-110 \mathrm{~cm}$ alt., isolada ou formando touceiras, epífita, mesofítica. Folhas 20-27, 41-57 cm compr., suberetas, formando roseta infundibuliforme, ampla; bainha 13-14 × 8-9 cm, ovais, densamente lepidotas, castanha escura; lâmina 26-33 × 5-7 cm, linear, ápice obtuso-acuminado, levemente lepidotas em ambas as faces, verdes, com estrias verde-escuras, transversais, sinuosas, irregularmente dispostas. Escapo 52-54 × 0,4-0,8 cm, superando as folhas, ereto ou subereto, glabro; brácteas do escapo amplexicaules, superiores ca. 4,5 × 3,2 cm, ovais, ápice obtuso-acuminadas, maiores que os entrenós, levemente imbricadas, róseas; inferiores ca. $9 \times 4$ $\mathrm{cm}$, oval, ápice obtuso-acuminadas, maiores que os entrenós, levemente imbricadas, verdes, com base rósea. Inflorescência racemo, 30-32 cm compr., 14-27 flores, dísticas, patentes, distanciadas entre sí por $1-1,5 \mathrm{~cm}$, laxa, robusta, raque ereta ou levemente recurvada, glabro, verde a levemente rósea. Bráctea floral amplexiflora 2,7-3,5 × 2,6-3,0 $\mathrm{cm}$, oval a largo-elíptica, ápice arredondado, margens hialinas, mais curta que as sépalas, densamente mucilaginosa, coriácea, levemente lepidota, rósea. Flores 4,2-4,7 cm de compr., curto pediceladas, pedicelo $1,0 \mathrm{~cm}$ compr.; sépalas 3,5-
3,9 × 1,6-2,0 cm, oblongas, ápice arredondado, livres, imbricadas, amarelo-esverdeadas; pétalas ca. $3,7-3,9 \times 1,4-1,6 \mathrm{~cm}$, oblongas, retusas, reflexas na antese, membranáceas, amarelo-esverdeadas, conatas na base por ca. $0,2 \mathrm{~cm}$, formando uma corola urceolada; 2 apêndices petalíneos adnatos à base, ca. $0,7 \times 0,4 \mathrm{~cm}$, ovais, levemente denteados no ápice; estames inclusos, 3,0-3,2 cm compr., radiais, coniventes; filete ca. 2,5 cm compr., livres, sigmoides, achatados dorso-ventralmente, alargados em direção ao ápice, amarelos; anteras ca. 1,0 cm compr., introrsas, dorsifixas, rimosas, não-versáteis, amarelas; ovário $0,9 \times 0,5 \mathrm{~cm}$, oval, esverdeado; estilete $2-3 \mathrm{~cm}$ compr.; estigma ca. 0,1 $\mathrm{cm}$ compr., laminar-convoluto, alvo-amarelado. Fruto ca. 4,5 cm compr., fusiforme. Sementes ca. $0,4 \mathrm{~cm}$ compr., fusiforme.

Material selecionado: BRASIL. PARANÁ: Balsa Nova, Serra de São Luís do Purunã, 06.XII.1985, fl., J. Silva \& F. Zelma 29 (FUEL); 08.X.2011, fl., V. Kowalski \& R. Kowalski 22 (HUPG). Campina Grande do $\mathrm{Sul}_{2}$ Serra do Capivari, 30.XI.1998, fl., Y. Kuniyoshi \& C. Roderjan 6.216 (EFC). Castro, Estrada Castro-Tibagi, 28.XI.2011, f1., M. Engels 319 (HUPG). Mandirituba, 18.IV.2012, fr., V. Kowalski \& S. Miyamoto 47 (HUPG). Piraquara, APA Estadual Piraquara, 14.XII.2011, fr., V. Kowalski \& S. Miyamoto 31 (HUPG). Ponta Grossa, Alagados, 20.IX.2012, fl., V. Kowalski et al. 59 (HUPG); Buraco do Padre, 18.V.2011, fr., V. Kowalski et al. 15 (HUPG); Cachoeira da Mariquinha, fl., 05.IX.2012, V. Kowalski et al. 58 (HUPG); Cachoeira do Rio São Jorge, 28.IX.2011, f1., V. Kowalski et al. 19 (HUPG).

Vriesea platynema é caracterizada pelas pétalas maiores em comparação às sépalas e o filete alargado e achatado dorso-ventralmente próximo a região do conectivo, característica que originou o nome da espécie. 

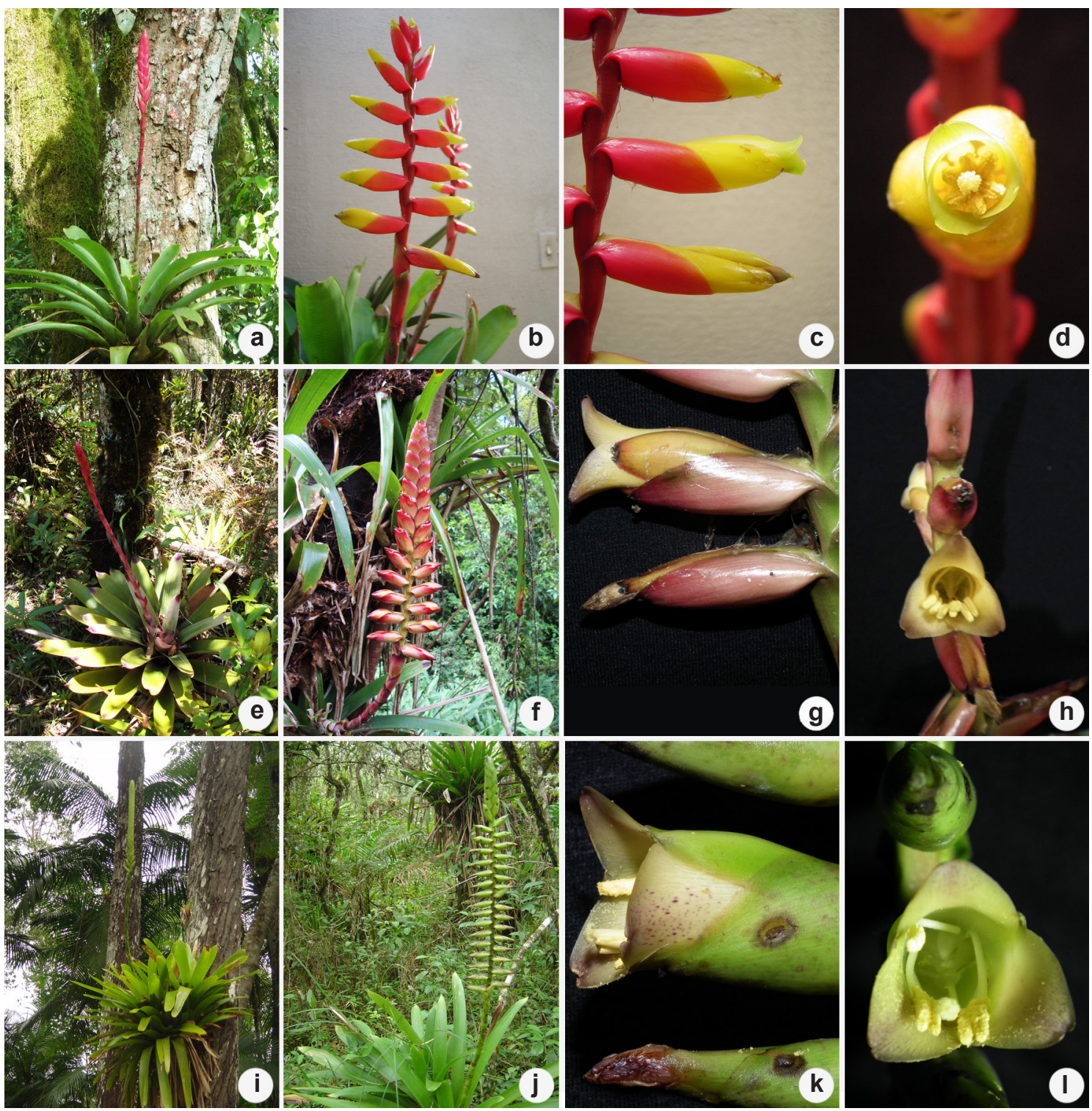

Figura 2 -a-d. Vriesea platynema Gaudich. var. platynema - a. hábito; b. inflorescência; c. vista lateral da flor, corola urceolada; d. vista frontal da flor. e-h. Vriesea platynema var. variegata (Guillon) Reitz. - e. hábito; f. inflorescência; g. vista lateral da flor, corola campanulada; $h$. vista frontal da flor. i-1. Vriesea tijucana E. Pereira - i. hábito epifítico; j. inflorescência; $k$. vista lateral da flor; 1 . vista frontal da flor.

Figure 2 - a-d. Vriesea platynema Gaudich. var. platynema - a. habit; b. inflorescence; c. flower, lateral view, corolla urceolate; d. flower, frontal view - e-h. Vriesea platynema var. variegata (Guillon) Reitz - e. habit; f. inflorescence; g. flower, lateral view, corolla campanulate; h. flower, frontal view. i-1. Vriesea tijucana E. Pereira - i. epiphytic habit. j. inflorescence; k.flower, lateral view; l. flower, frontal view.

A forma da corola urceolada de $V$. platynema var. platynema (Fig.3h) a distingue de V. platynema var. variegata. Apresenta mucilagem fluída, incolor e inodora, entre as brácteas florais e as sépalas. Observações em campo indicam a antese aproximadamente entre $08 \mathrm{~h} 00$ e fechamento das flores por volta das $22 \mathrm{~h} 00$, contudo, não foi observada a visitação de polinizadores. Floresce de setembro a dezembro, com frutos de fevereiro a março.

Os exemplares coletados no Paraná apresentam hábito epifitico, entre 3 a 15 m alt. e são heliófilas e mesofiticas. Ocorrem nas regiões de Floresta Ombrófila Mista e Campos, desde Curitiba até Prudentópolis, entre o $2^{\circ}$. e $3^{\circ}$. planalto Paranaense (Fig.1). 
Vriesea platynema var. platynema não apresenta-se ameaçada, possui uma extensão de ocorrência de $31.116 .41 \mathrm{Km}^{2}$ e uma área de ocupação de aproximadamente $8.900 \mathrm{Km}^{2}$ dentro do território Paranaense, onde foram encontrados 13 pontos de ocorrência.

Vriesea platynema var. variegata (Guillon) Reitz., Anais Bot. Herb. Barbosa Rodrigues 4:15. 1952.

Basiônimo: Encholirion roseum var. varigatum Guillon., Rev. Hort. 55: 470. 1883. Typus: Leste do Brasil, Sem localidade exata, s.d, Jacob Makoy Hortus s.n. (Holotypus: LG n.v.).

Figs: 2e-h, 4a-o

Planta florida, 110-135 cm alt., isolada ou formando touceiras, epífita, humícola ou rupícola, mesofítica ou xerofítica. Folhas 27-35, 35-53 cm compr., suberetas, formando roseta infundibuliforme, ampla; bainha 9-13 × 8-10 cm, elíptica, densamente lepidota, castanha escura, vinácea próximo a lâmina; lâmina 28-40 × 5-7 cm, linear, ápice obtuso-acuminado, levemente lepidota, face adaxial verde com estrias longitudinais alvas nas folhas mais jovens, mácula arroxeada ou avermelhada no ápice. Escapo 71-76 × $1 \mathrm{~cm}$, superando as folhas, ereto ou subereto, glabro; brácteas do escapo amplexicaules, superiores 5,5-7 × 3-4 cm, largoovais, acuminadas, recurvadas, maiores que os entrenós, levemente imbricadas, glabras, vináceas; inferiores, 9,6-9,8 $\times 3-4 \mathrm{~cm}$, oval, maiores que os entrenós, levemente imbricadas, ápice acuminado, levemente recurvadas, glabras, verdes com base e ápice vináceo. Inflorescência racemo, 26-30 cm compr., 20-36 flores, dísticas, patentes, distanciadas entre sí 1,0-1,5cm, laxa, robusta, raque ereta, glabro, verde clara. Bráctea floral amplexiflora, 3-4 × 3-4 $\mathrm{cm}$, largo-elíptica a largo-oval, ápice arredondado, mais curtaque as sépalas, mucilaginosa, coriácea, levemente lepidota, vinácea. Flores $4-5 \mathrm{~cm}$ de compr., curto pediceladas, pedicelo $1,0 \mathrm{~cm}$ compr., sépalas 3,1-3,2 × 1,6-2,0 cm, elípticas, ápice obtuso, livres, imbricadas, amarelo-acastanhadas com bordas e ápice vináceo; pétalas 3,5-3,8 × 1,6-2,0 $\mathrm{cm}$, oblonga, ápice obtuso, levemente reflexas na antese, membranáceas, amarelas com ápice levemente vináceo, conatas na base por ca. $0,2 \mathrm{~cm}$, corola campanulada, 2 apêndices petalíneos adnatos à base, ca. 1,0 0 0,5 cm, oval, ápice atenuado; estames inclusos, 3,1-3,3 cm compr., filete ca. $2,5 \mathrm{~cm}$ compr., livres, levemente sigmoides, achatados dorsoventralmente, levemente alargados em direção ao ápice, amarelos; anteras ca. 1,0 cm compr., introrsas, dorsifixas, rimosas, não-versáteis, amarelas; ovário ca. $0,7 \times 0,5 \mathrm{~cm}$, oval; estilete $2,8-3,0 \mathrm{~cm}$ compr.; estigma ca. $0,1 \mathrm{~cm}$ compr., laminar-convoluto, alvo-amarelado. Fruto ca. $4,3 \mathrm{~cm}$ compr, fusiforme. Sementes ca. 0,2 cm compr., fusiforme.

Material selecionado: BRASIL. PARANÁ: Guaratuba, Serra de Araçatuba, Morro dos Perdidos, 27.V.2011, fr., V. Kowalski et al. 09 (HUPG); Pico Piraí, 13.X.2006, fl., R. Morokawa \& L. Sampaio 97 (UPCB). Morretes, Estrada Curitiba-Paranaguá, 15. IX.1953, fl., R. Reitz 5765 (HBR); Parque Estadual Pico Marumbi, 07.XII.2011, Fl., $V$ Kowalski et al. 29 (HUPG). Quatro Barras, encosta do Morro Mãe Catira, 12.I.1967, fl., G. Hatschbach 15.697 (HBR); estrada da Graciosa, 19.X.2011, fl., S. Miyamoto \& F. OIiveira 68 (HUPG); Rio das Cascatas, 14.XII.2007, fl., A. Cervi \& R. Tardivo 9348 (HUPG, UPCB); Serra da Baitaca, Morro Anhangava, 16.XI.2011, f1., V. Kowalski et al. 28 (HUPG); Morro Anhangava, base do morro, 23.II.2012, fr., V. Kowalski \& S. Miyamoto 34 (HUPG).

Vriesea platynema var. variegata tem forma de vida epífita, humícola, mesofítica ou xerofítica, ocorrendo nas regiões de Floresta Ombrófila Densa, incluindo locais com elevadas altitudes, onde ocorre como terrestre (Fig. 2e). Quando epífitas, apresenta escapo floral levemente inclinado, afastado do forófito (Fig. 2f), possivelmente uma forma da planta ficar mais visível ao polinizador, já que está competindo por área com outras epífitas.

Caracteriza-se pela roseta ornamental com estrias longitudinais alvas e ápice vináceo, observado nas folhas mais jovens (Fig. 2e). Apresenta mucilagem densa, incolor entre as brácteas florais e as sépalas. Possui antese noturna e odor desagradável, possivelmente relacionado quiropterofilia, já relatado no gênero por Sazima et al. (1995).

Em campo, pode ser diferenciada pela corola campanulada (Fig. 2g, 4i), além da ornamentação das folhas, características estas, que não observadas em $V$. platynema var. platynema, que possui corola urceolada, e folhas verdes em ambas as faces. Coletada com flores entre os meses de setembro a dezembro, e maturação dos frutos em fevereiro e março.

Reitz (1952) ao combinar o táxon no gênero Vriesea não citou material testemunho depositado em herbário. Smith \& Downs (1977) citaram o typus depositado no herbário do Museu de Paris (n. v.), na mesma obra os autores citam como material analisado a amostra Reitz 5765 (HBR 6666), sendo este material, tomado como referência neste trabalho.

Para o estado do Paraná, V. platynema var. variegata (Guillon) Reitz apresenta-se em perigo (EN) de acordo com os critérios B1 B2 b (i,ii, iii, iv). O táxon é encontrado em uma área de extensão de 


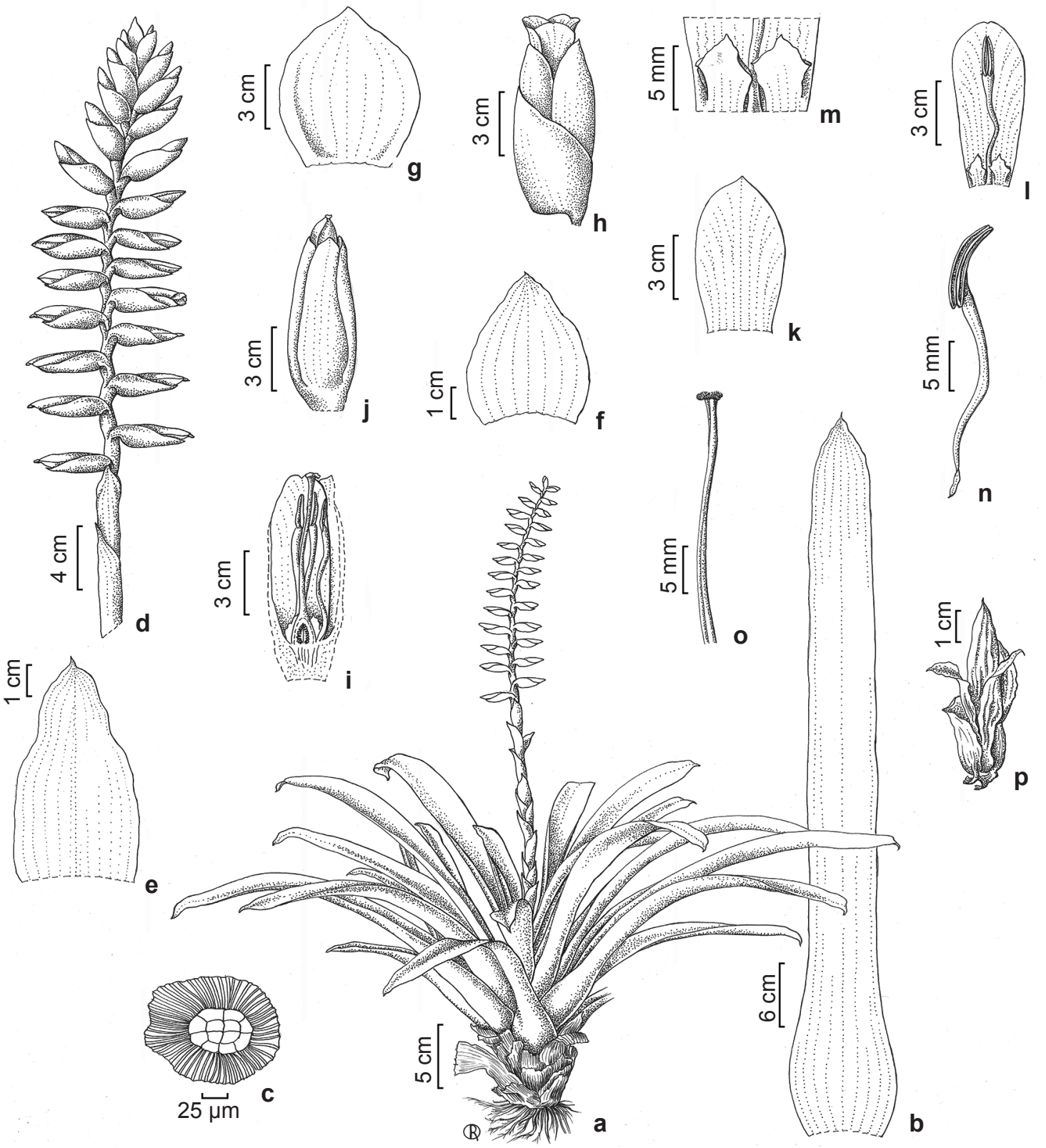

Figura 3 - a-p. Vriesea platynema Gaudich. var. platynema (V. Kowalski et al. 57 HUPG); a. hábito; b. folha; c. tricoma peltado; d. inflorescência; e. bráctea do escapo inferior; f. brácteas do escapo superior; g. bráctea floral; h. flor; i. corte longitudinal da flor; j. flor após a antese; k. sépala; 1. pétala; m. detalhe dos apêndices petalíneos; n. estame; o. estigma; ( $V$. K. Kowalski et al. 32 HUPG); p. fruto antes da deiscência.

Figure 3 - a-p.Vriesea platynema Gaudich. var. platynema (V. Kowalski et al. 57 HUPG); a. habit; b. leaf; c. peltate trichome; d. inflorescence; e. lower scape bracts; f. upper scape bracts; g. floral bracts; h. flower; i. flower, longitudinal view; j. flower after anthesis; k. sepal; 1. petal; m. detail of petal appendages; n. stamen; o. stigma; (V. K. Kowalski et al. 32 HUPG); p. fruit.

ocorrência de 526,23 $\mathrm{Km}^{2}$ e uma área de ocupação de aproximadamente $184,00 \mathrm{Km}^{2}$, restrita à Serra do Mar, com maior número de populações na Serra da Graciosa. Devido à coloração de suas folhas, esta planta é utilizada como ornamental e tem sido retirada indiscriminadamente de seu habitat natural. Vriesea tijucana E. Pereira, Rodriguésia 26 (38): 116. 1971. Typus: Brasil. Rio de Janeiro: Floresta 

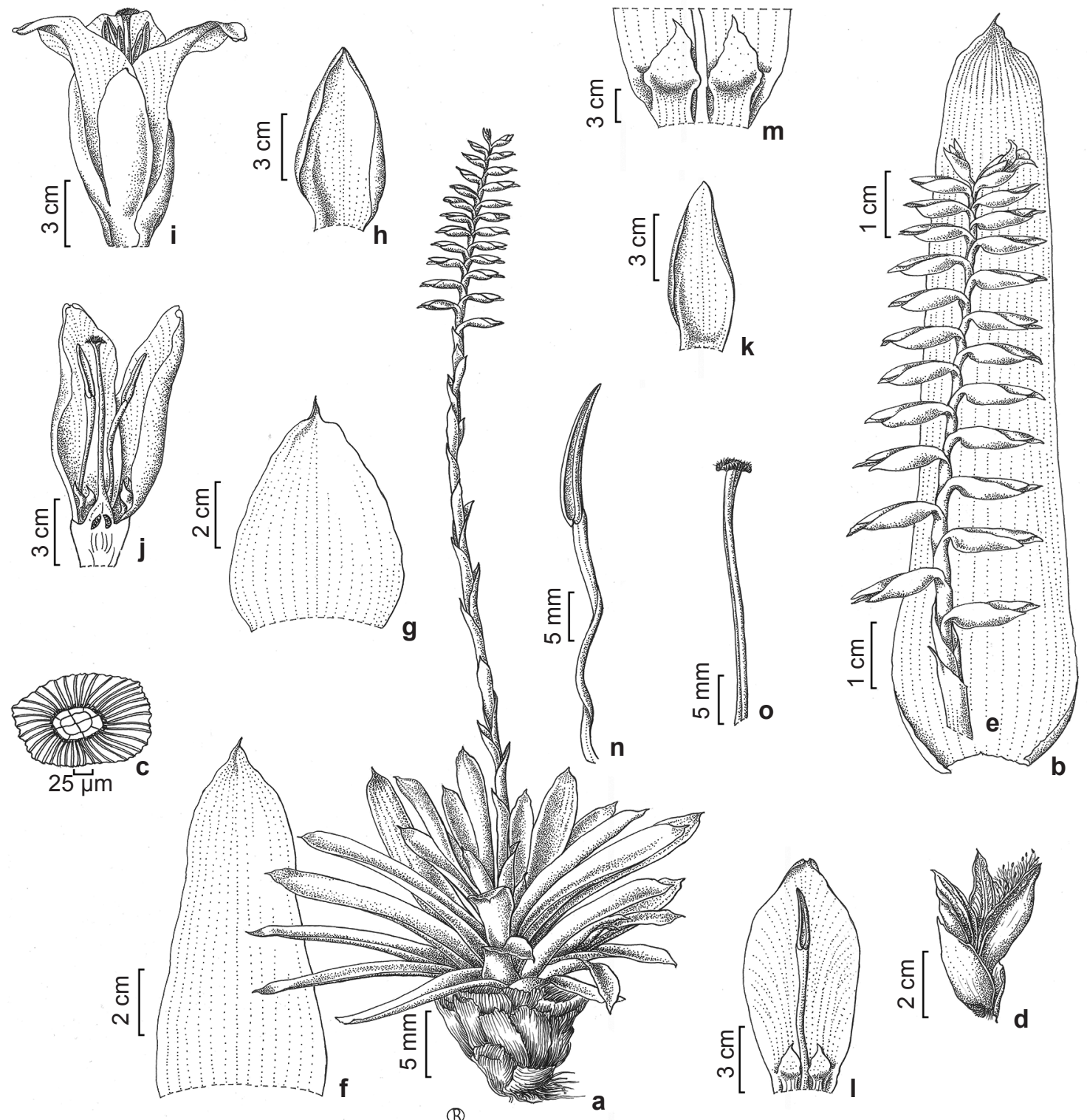

(B)
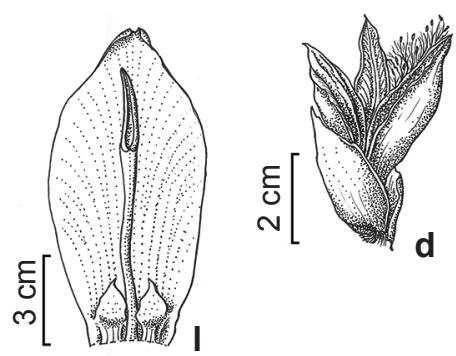

Figura 4 - a.o. Vriesea platynema var. variegata (Guillon) Reitz. (V. K. Kowalski et al. 09 HUPG) - a. hábito; b. folha; c. tricoma peltado; d. fruto aberto; (V.K. Kowalski \& S.N.A. Miyamoto 60 HUPG); e. inflorescência; f. bráctea do escapo inferior; g. bráctea do escapo superior; h. bráctea floral; i. flor; j. corte longitudinal da flor; k. sépala; 1. pétala; $m$. detalhe dos apêndices petalíneos; n. estame; o. estigma laminar-convoluto.

Figure 4 -a-o. Vriesea platynema var. variegata (Guillon) Reitz. (V. K. Kowalski et al. 09 HUPG) - a. habit; b. leave; c. peltate trichome; d. open fruit; (V.K. Kowalski \& S.N.A. Miyamoto 60 HUPG); e. inflorescence; f. lower scape bracts; g. upper scape bracts; h. floral bracts; i. flower; j. flower, longitudinal view; k. sepal; l. petal; m. detail of petal appendages; n. stamen; o. stigma.

da Tijuca, 17.II.1968, fl., E. Pereira 16685 (holotypus RB 140866; isotypus HB [imagem!]).

Figs: $2 \mathrm{i}-1,5 \mathrm{a}-\mathrm{q}$

Planta florida, $130-160 \mathrm{~cm}$ alt., isolada ou formando touceiras, epífita, mesofítica. Folhas 30-
$45,60-80 \mathrm{~cm}$ compr., suberetas, formando roseta infundibuliforme, ampla; bainha 13-15 × 9-10 cm, elíptica, densamente lepidota, castanho-escura; lâmina 43-65 × 6,3-7,5 cm, lanceolada, com ápice obtuso-acuminado à atenuado, levemente lepidotas 
em ambas as faces, verdes com estrias diagonais verde-escuras, regularmente dispostas. Escapo $84-90 \times 1,5 \mathrm{~cm}$, superando as folhas, ereto, glabro; brácteas do escapo amplexicaules, densamente mucilaginosas, superiores $6,0 \times 3,5-4,5 \mathrm{~cm}$, oval, ápice obtuso à obtuso-acuminado, maiores que os entrenós, levemente imbricadas, verdes; inferiores 10-11 × 4-5 cm, oval, ápice acuminado, maiores que os entrenós, levemente imbricadas, verdes. Inflorescência racemo, 55-90 cm compr., 40-70

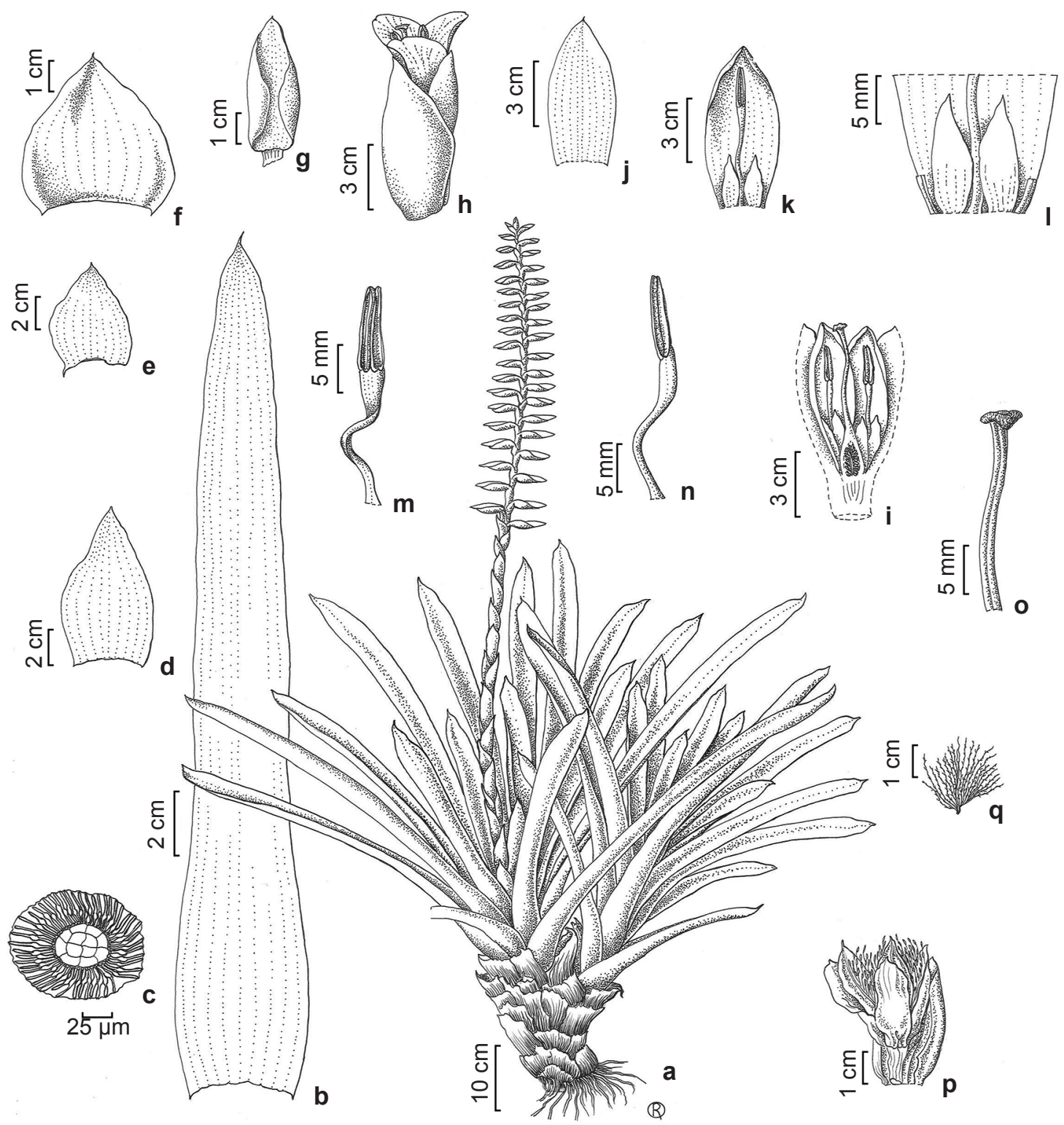

Figura 5 - a-q.Vriesea tijucana E. Pereira. (V.K. Kowalski et al. 49 HUPG); a. hábito; b. folha; c. tricoma peltado; d. bráctea do escapo inferior; e. bráctea do escapo superior; f. bráctea floral aberta; g. bráctea floral; h. flor; i. corte longitudinal da flor; j. sépala; k. pétala; 1 . detalhe dos apêndices petalíneos; $m$. vista frontal do estame; $n$. vista lateral do estame; o. estigma ( $V . K$. Kowalski 17 HUPG); p. fruto; q. semente.

Figura 5 - a-q.Vriesea tijucana E. Pereira. (V.K. Kowalski et al. 49 HUPG); a. habit; b. leave; c. peltate trichome; d. lower scape bract; e. upper scape bract; f. open floral bract; g. floral bract; h. flower; i. flower, longitudinal view; j. sepal; k. petal; 1. detail of petal appendages; m. stamen, front view; n. stamen, lateral view; o. stigma ( $V$. K. Kowalski et al. 17 HUPG); p. fruit; q. seed. 
flores, dísticas, patentes, distanciadas entre sí por 2,0-2,5 cm, laxa, robusta, raque ereta, verde escura. Bráctea floral 4,5-4,9 × 4-4,5 cm, largo-oval, amplexiflora, ápice obtuso, mais curta ou igualandose as sépalas, densamente mucilaginosa, coriácea, levemente lepidota, verde com máculas marrons. Flores 5-5,6 cm de compr., pedicelo ca. $1,5 \mathrm{~cm}$ compr.; sépalas 2,5-3,5 × 1,2-1,7 cm, elípticas, obtuso-apiculados, livres, imbricadas, verdes, com bordas laterais vináceas; pétalas 3,5-3,8 ×2-2,2 cm, oboval a elípticas, retusos, membranáceas, reflexas na antese, castanho-claras com máculas vináceas próximo ao ápice, conatas na base por ca. $0,2 \mathrm{~cm}$, formando uma corola campanulada, com 2 apêndices petalíneos adnatos à base, $1,0 \times 0,5 \mathrm{~cm}$, elípticos, ápice atenuado; estames inclusos, 3,3-3,6 cm compr., filetes ca. $2,6 \mathrm{~cm}$ compr., livres, fortemente sigmoides, achatados dorso-ventralmente, alargados em direção ao ápice, amarelos; anteras ca. $1,0 \mathrm{~cm}$ compr., introrsas, dorsifixas, rimosas, não-versáteis, amarelas. Ovário oval, ca. $0,8 \times 0,5 \mathrm{~cm}$, esverdeado; estilete 3,0-3,2 cm compr.; estigma $0,2 \mathrm{~cm}$ compr., laminar-convoluto, alvo-amarelado. Fruto ca. $5 \mathrm{~cm}$ compr., fusiforme. Sementes ca. 0,4 cm compr., fusiforme.

Material selecionado: BRASIL. PARANÁ: Estrada Curitiba-Joinvile, 14.I.1951, fr., R. Reitz 3888 (HBR). Guaraqueçaba, 15.III.2012, fl., V. Kowalski et al. 37 (HUPG). Ilha de Superagui, 13.VII.2011, fr., V. Kowalski et al. 17 (HUPG). Guaratuba, 03.II.1952, fr., R. Reitz 4.270 (HBR); 20.II.1952, fl., R. Reitz 4666 (HBR). Matinhos, Parque Estadual Rio da Onça, 25.IV.2012, fl., V. Kowalski et al. 48 (HUPG). Paranaguá, Rio Guaraguaçu, 23.V.2012, fl., V. Kowalski et al. 55 (HUPG).

Vriesea tijucana apresenta hábito epifítico, entre 2 a 10 m alt., mesofítica, ocorrendo nas regiões de Floresta Ombrófila Densa, principalmente de terras baixas (Fig.1). Os exemplares do Paraná apresentam antese noturna, mucilagem densa entre as brácteas florais e as sépalas e entre as brácteas e o escapo, diferenciando-os das demais espécies aqui estudadas. Caracteriza-se ainda, pelo odor agradável e cítrico. Com floração de março a junho, e maturação dos frutos em julho e agosto.

Em campo, quando florida, dificilmente é confundida com as outras espécies afins, pois, de maneira geral, é uma planta mais robusta, com altura acima de $130 \mathrm{~cm}$.

As brácteas do escapo possuem a mesma forma e coloração em toda a sua extensão, e a inflorescência possui entre 40 à 70 flores, maior que o observado em $V$. platynema var. platynema $\mathrm{e}$ V. platynema var. variegata (Fig. 2i-1, 5a).
Em sua descrição original, há relatos da afinidade com $V$. bituminosa Wawra, distinguindo-a pelo comprimento das brácteas florais, ápice das folhas e ausência da substância betuminóide. A espécie foi identificada erroneamente em obras importantes, como em Smith e Downs (1977) sendo citada como Vriesea jonghei (K. Koch) E. Morren e em Reitz (1983) como Vriesea atra Mez (Moura 2011).

Moura (2011) relatou que o táxon apresenta variações morfológicas ao longo de sua distribuição, desde Pernambuco até Santa Catarina (Forzza et al. 2014), onde podem ser identificados diferentes morfo-tipos, com pequenas variações, como tamanho da flor, distância entre elas e a forma da corola.

Para o estado do Paraná, V. tijucana apresentase em perigo (EN) de acordo com os critérios B1 B2 a,b (i,ii,iii). A espécie possui uma área de extensão de ocorrência de $520,43 \mathrm{Km}^{2}$, e uma área de ocupação de aproximadamente 192,00 $\mathrm{Km}^{2}$, onde quatro pontos de ocorrência foram localizados, sendo três destes, em áreas de proteção ambiental (APA de Guaraqueçaba, Parque Nacional Ilha de Superagui e P.E. Rio da Onça), e uma, em área urbana em desenvolvimento (Paranaguá, Rio Guaraguaçu).

\section{Agradecimentos}

Ao CNPq, a concessão da bolsa de Mestrado e o apoio ao projeto PROTAX- Estudos taxonômicos com Monocotiledôneas no estado do Paraná, com ênfase em Bromeliaceae e Orchidaceae. Ao IAP por conceder a autorização de coleta nas unidades de conservação do Paraná e aos curadores e técnicos dos herbários visitados, a hospitatlidade e atenção recebida. À Rosane Quintella, a confecção das ilustrações.

\section{Referências}

Benzing, D. 2000. Bromeliaceae: Profile of an Adaptative Radiation. Cambridge Press, New York. 714p.

Brown, G. \& Gilmartin, A. 1989. Stigma types in Bromeliaceae: A Systematic Survey. Systematic Botany 1: 110-132.

Costa, A. 2002. Revisão Taxonômica do Complexo Vriesea paraibica Wawra (Bromeliaceae). Tese de Doutorado. Universidade de São Paulo, São Paulo. $187 \mathrm{p}$.

Forzza, R.; Costa, A.; Siqueira-Filho, J.; Martinelli, G.; Monteiro, R.; Santos-Silva, F.; Saraiva, D.; Paixão-Souza, B.; Louzada, R. \& Versieux, L. 2014. Bromeliaceae. In: Lista de Espécies 
da Flora do Brasil. Jardim Botânico do Rio de Janeiro. Disponível em <http://floradobrasil.jbrj. gov.br/jabot/floradobrasil/FB6414>. Acesso em 2 dezembro 2014.

Fidalgo, O. \& Bononi, V. 1984. Técnicas de coleta, preservação e herborização de material botânico. Instituto de Botânica, São Paulo. 62p.

Givinish, T.; Millan, K.; Berry, P. \& Sytsma, K. 2007. Phylogeny adaptive radiation and historical biogeography of Bromeliaceae inferred from $n d h F$ sequence data. Aliso 23: 3-26.

Givinish, T.; Barfuss, M.; Van Ee, B.; Riina, R.; Schulte, K.; Horres, R.; Gonsiska, P.; Jabaily, R.; Crayn, D.; Smith, J.; Winter, K.; Broun, G.; Evans, T.; Holst, B.; Luther, H.; Till, W.; Ziska, G.; Berry, P. \& Sytsma, K. 2011. Philogeny, adaptative radiation, and historical Biogeography in Bromeliaceae: Insights from an eight-locus plastid philogeny. American Journal of Botany 98: 1-24.

Givinish, T.; Barfuss, M.; Van Ee, B.; Riina, R.; Schulte, K.; Horres, R.; Gonsiska, P.; Jabaily, R.; Crayn, D.; Smith, J.; Winter, K.; Broun, G.; Evans, T.; Holst, B.; Luther, H.; Till, W.; Ziska, G.; Berry, P. \& Sytsma, K. 2014. Adaptative radiation, correlated and contingent evolution, and net species diversification in Bromeliaceae. Molecular Phylogenetics and Evolution 71: 55-78.

Gomes-da-Silva, J.; Vargens, F.; Arruda, R. \& Costa, A. 2012. A Morphological Cladistic Analysis of the Vriesea corcovadensis Group (Bromeliaceae: Tillandsioideae), with Anatomical Descriptions: New Evidence of the Non-Monophyly of the Genus. Systematic Botany 37: 641-654.

Gonçalves, E. \& Lorenzi, H. 2011. Morfologia Vegetal: organografia e dicionário ilustrado de morfologia das plantas vasculares. $2^{\mathrm{a}}$ ed. Instituto Plantarum de Estudos da Flora, São Paulo. 544p.

IUCN - International Union for Conservation of Nature. 2001. Red List Categories and Criteria: version 3.1. IUCN Species Survival Commission. IUCN, Gland, Switzerland and Cambridge. 30p. Disponível em <http://www.iucnredlist.org/static/categories criteria_3_1>. Acesso em 3 março 2014.

IUCN - International Union for Conservation of Nature. 2012. Guidelines for Application of IUCN Red List Criteria at Regional and National Levels: version 4.0. Gland, Switzerland and Cambridge. 41p.
Disponível em <http:// www.iucn.org/about/work/ programmes/species/our_work/the iucn red list/ resources/guidelines_application/>. Acesso em 3 março 2014.

Luther, H. 2012. An alphabetical list of bromeliad binomials. $12^{\circ}$ ed. The Bromeliad Society International. The Marie Selby Botanical Gardens, Sarasota \& Bromeliad Society International, Sarasota. 44p.

Martinelli, G.; Vieira, C.; Gonzales, M.; Leitman, P.; Piratininga, A.; Costa, A. \& Forzza, R. 2008. Bromeliaceae da Mata Atlântica Brasileira: lista de espécies, distribuição e conservação. Rodriguésia 59: 209-258.

Moura, R. 2011. Revisão Taxonômica do Grupo Vriesea platynema Gaudich. (Bromeliaceae). Tese de Doutorado. Universidade Federal do Rio de Janeiro, Rio de Janeiro. 194p.

Radford, A.; Dickson, W.; Massey, J. \& Bell, C. 1974. Vascular Plants Systematics. Harper \& Row, New York. 891p.

Reitz, R. 1952. Species, varietates, combinations novae et criticae Bromeliacearum Catharinensium (Brasilia). Anais Botânicos do Herbário Barbosa Rodrigues 4:7-36.

Reitz, R. 1983. Bromeliaceas e a Malária - Bromélia Endêmica. In: Teitz, R. Flora Ilustrada Catarinense, parte I, fascículo Bromeliaceae. Herbário Barbosa Rodrigues, Itajaí. 608p.

Roderjan, C..; Galvão, F.; Kunyoshi, Y. \& Hatschbach, G. 2002. As unidades fitogeográficas do estado do Paraná. Ciência \& Ambiente 24: 75-92.

Sazima, M.; Buzato, S. \& Sazima, I. 1995. Polinização de Vriesea por morcegos no Sudeste brasileiro. Bromélia 2: 29-36.

Scharf, U. \& Gouda, E. J. 2008. Bringing Bromeliaceae back to homeland botany. Journal of the Bromeliad Society 58: 123-129.

Smith, L. 1955. The Bromeliaceae of Brazil. Smthsonian Miscellaneous Collections 126: 1- 290.

Smith, L. \& Downs, R. 1977. Tillandsioideae (Bromeliaceae). Flora Neotropica Monograph 14: 663-1492.

Wanderley, M. \& Martins, S. 2007. Bromeliaceae. In: Wanderley, M.; Shepherd, G. \& Giulietti, A. Flora fanerogâmica do estado de São Paulo. Instituto de Botânica, São Paulo. Vol 5, 494p. 


\section{Lista de Exsicatas:}

Barbosa, E. 689 (2). Bresolin, A. 445 (1). Britez, R. 1.316 (3). Cervi, A. 9.348 (2). Costa, A. 452 (1). Dombrowski, L. 2.237 (1), 6.726 (2). Engels, M. 319 (1). Hatschbach, G. 15258 (2), 15697 (2), 17668 (1), 29795 (1), 58.156 (1). Kowalski, V. 05 (1), 06 (1), 08 (1), 09 (2), 10 (2), 14 (2), 15 (1), 16 (1), 17 (3), 18 (3), 19 (1), 20 (1), 21 (1), 22 (1), 23 (1), 26 (2), 28 (2), 29 (2), 30 (2), 31 (1), 32 (1), 33 (1), 34 (2), 37 (3), 38 (3), 44 (2), 45 (2), 46 (2), 47 (1), 48 (3), 49 (3), 55 (3), 57 (1), 58 (1), 59 (1), 60 (2). Kersten, R. 724 (1). Klein, R. 6.874 (1), 7.070 (1), 9780 (1). Kummrow, R. 2.404 (2). Kuniyoshi, Y. 6.102 (3), 6216 (1). Leite, J. 2160 (1). Leme, E. 651 (1), 1.670 (1), 1.669 (2). Lindeman, J. 2930 (1). Martinelli, G. 14880 (1), 14916 (1), 14996 (1). Miyamoto, S. 37 (1), 68 (2), 69 (2), 72 (2), 73 (2). Morokawa, R. 63 (2), 97 (2), 107 (2). Plaumann, F. 186 (1). Poliquesi, C. 238 (2). Reitz, R. 950 (1), 778 (1), 3377 (1), 3637 (1), 3644 (3), 3888 (3), 3859 (1), 3925 (1), 3991 (1), 4.270 (3), 4666 (3), 5765 (2), 6920 (1), 7222 (1), 7265 (1), 7513 (1), 7551 (1), 8658 (1), 9.789 (3), 10885 (3), 15258 (2), 15697 (2). Silva, J. 29 (1), 1204 (2), 2645 (2), 3901 (1). Smith, L. 11719 (1). Ziller, S 122 (2). 